\title{
Implant-based immediate breast reconstruction: failure rate when radiating the tissue expander or the permanent implant-a meta-analysis
}

\author{
Víctor Fuertes ${ }^{1}$, Mónica Francés ${ }^{2}$, José M. Casarrubios $^{2}$, Javier Fernández-Palacios ${ }^{2}$, \\ Jesús María González ${ }^{3}$, Juan Francisco Loro-Ferrer ${ }^{4}$ \\ ${ }^{1}$ Department of Plastic Surgery, Vancouver General Hospital, Vancouver, Canada; ${ }^{2}$ Department of Plastic Surgery, ${ }^{3}$ Research Department, University \\ Hospital Dr. Negrín, Las Palmas de Gran Canaria, Spain; ${ }^{4}$ Clinical Pharmacology, Medicine School-University of Las Palmas de Gran Canaria, Las \\ Palmas de Gran Canaria, Spain \\ Contributions: (I) Conception and design: V Fuertes; (II) Administrative support: J Fernández-Palacios, JF Loro-Ferrer; (III) Provision of study \\ materials or patients: V Fuertes; (IV) Collection and assembly of data: V Fuertes, M Francés, JM Casarrubios; (V) Data analysis and interpretation: V \\ Fuertes, JM González; (VI) Manuscript writing: All authors; (VII) Final approval of manuscript: All authors. \\ Correspondence to: Víctor Fuertes. Plastic, Reconstructive \& Aesthetic Surgery Specialist Physician. Department of Plastic Surgery (International \\ Fellow), Vancouver General Hospital, Vancouver, Canada. Email: vfuertesbielsa@gmail.com.
}

Background: Implant-based immediate approach remains to be a first line option for reconstruction of mastectomy defects. When combined with post-mastectomy radiation therapy (PMRT) two different schemas are possible: radiating the temporary tissue expander (TTE) or the permanent implant (PI). The present article intends to be the biggest cohort meta-analysis to the date comparing reconstructive failure (RF) rate in these two scenarios: PMRT to TE compared with PMRT to PI.

Methods: A systematic search of the literature was performed on PUBMED/MEDLINE. The following key words were chosen: Breast Reconstruction AND Implant based AND Immediate. The time limit applied was from January 2008 to January 2019. We selected ten articles $(n=1,130)$ to perform a meta-analysis due to the similarity of their approaches. Secondly, we did a simple literature review in order to identify some variables possibly working as predicting factors for RF.

Results: Previous meta-analysis are analysed. Some variables possibly working as risk factors for RF are summarized. We performed a meta-analysis in two scenarios: a fixed-effect model and a random effect model. For the random effect model an $\mathrm{OR}$ of 1.85 was obtained $(0.96,3.57 ; \mathrm{P}=0.067)$. A funnel plot is performed showing no publication bias exists.

Conclusions: There is a tendency towards a higher RF rate when the TTE is irradiated compared with the irradiation of the PI. Further studies trying to elucidate the influence of the suggested risk factors for RF have to be performed to stablish a consensus about the indications and contraindications of this reconstructive modality.

Keywords: Breast reconstruction; failure; implant; meta-analysis; radiotherapy

Submitted Sep 23, 2019. Accepted for publication Jan 04, 2020.

doi: 10.21037 /gs.2020.01.20

View this article at: http://dx.doi.org/10.21037/gs.2020.01.20 


\section{Introduction}

Mastectomies due to breast cancer and as contralateral prophylactic procedures have grown up during the last few years in the United States $(1,2)$. Parallel to this, several randomized trials in the field of Radiation Oncology have diminished the threshold for recommending postmastectomy radiation therapy (PMRT) from four-or-more positive axillary lymph node to the current recommendation (one-to-three), due to its probed capacity to decrease local recurrence and to improve survival rate (3-7).

Two steps prosthesis-based immediate or delayed breast reconstruction remains a regular procedure. During the decade 1998-2008, it was the most common reconstructive option in the States, even ahead of autologous reconstructions $(8,9)$. Different papers had demonstrated its oncological safety (10), good satisfaction levels from the cosmetic point of view as well as acceptable longterm outcomes (11). Thus, this reconstructive modality should be considered as a first line option for mastectomy reconstruction.

Even in the setting of the irradiated patient population, Agarwal et al. (12) demonstrated an increase in prosthesisbased reconstruction from $27 \%$ to $52 \%$, with the subsequent decrease in autologous reconstruction, over the past 10 years.

Immediate breast reconstruction improves patient body self-image and overall psychological well-being when compared with the delayed modality. Moreover, this reconstructive technique doesn't compromise the delivery of PMRT (13).

Concerns regarding the outcome of patients with a history of irradiation prior to the reconstruction or PMRT have motivated an important amount of papers during the last years, mainly in the context of Implant-based Immediate Breast Reconstruction (9,14-17). Its pathological effects during an acute and a chronic phase have been well described (18), with a maximal loss of endothelial cell and subsequent dermal deleterious changes occurring from months 2 to 6 (19). The combination of PMRT and Implant-based Immediate Breast Reconstruction has demonstrated to produce an increase in reconstructive failure (RF) rate as well as in some other complications (capsular contracture, infection...) (20-22). RF is mainly defined as the removal of implants with the inability to replace them, resulting in no final reconstruction or the need to add new salvage procedures. Nevertheless, its oncological safety and overall good patients and surgeon's satisfaction rates suggest not considering the need for PMRT as a primary universal contraindication for Implantbased Immediate Breast Reconstruction (23).

In the last few years, there has been an increase in the group of patients undergoing a mastectomy and an expander implantation in whom the need of PMRT remains uncertain (Mostly, Stage II Breast Cancer treated with neoadjuvant chemotherapy and undetermined lymph nodes status at the time of the surgery) (3). In addition, not all patients desire to delay breast reconstruction when radiotherapy is needed, nor some of them are willing/are candidates to undergo complex flap-based reconstructions.

Two different approaches regarding the timing of PMRT in the Implant-based Immediate Breast Reconstruction have been applied. The first consists of irradiation of the temporary tissue expander (TTE), and applying the radiotherapy during the expansion stage (RT to TTE), prior to TTE exchange to permanent implant (PI). This is the most common approach. The second approach consists of irradiating the PI when expansion stage and TTE-PI exchange procedure have already been completed (RT to PI).The latter is mainly used if adjuvant chemotherapy is being administered to the patient because it allows more time for the expansion (during the chemotherapy sessions) and makes safer the delay of the PMRT from 8 weeks up to 6 months after the end of the adjuvant chemotherapy $(13,24)$. The success of this sequence is very dependent in the coordination of the oncological team, which is not always easy to achieve. Its use is restricted in women receiving neoadjuvant chemotherapy as not more than 6 weeks from mastectomy to radiotherapy delivery could be accepted in this group in which a lot of them are suffering a stage III or more advanced breast cancer (3).

Several articles have compared cohorts using these two algorithms, focusing about which of them is better regarding the failure rate (25-34). From these papers, some meta-analysis has been performed but lack of consistent conclusions has been found due to several reasons (35-38). In addition, no further steps to analyze the predictors for the failure rate are available. Thus, this article, intends to be the largest cohort meta-analysis to date about the failure rate, contributing to new conclusions. Is there a better time to irradiate when doing an immediate implant-based breast reconstruction? Should we ideally irradiate the TE or the PI? By reviewing similar articles we also tried to elucidate question, what are the main factors that could be related with $R F$ in the setting of PMRT to PI/TTE? 


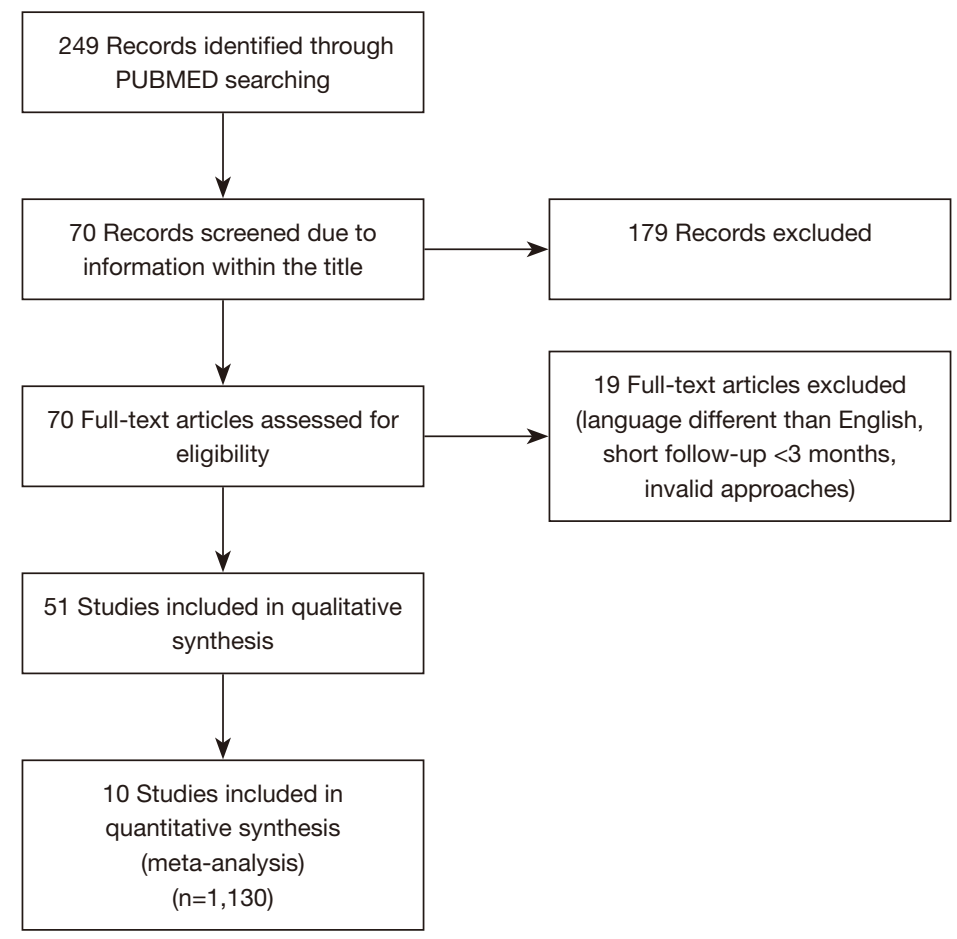

Figure 1 Flow chart.

\section{Methods}

A systematic search of the literature was performed on PUBMED/MEDLINE. The following key words were chosen: Breast Reconstruction AND Implant based AND Immediate. The time limit applied was from January 2008 to January 2019. A total of 249 results were found. We selected 51 of them. Articles not written in English, those not including at least one of RT schemas as well as those with short average follow-up times (less than 3 months) were excluded (Figure 1).

In the first part of the article, we selected ten articles $(\mathrm{n}=1,130)$ to perform a meta-analysis due to the similarity of their approaches. They are all Cohorts/Case-Controls retrospective or prospective studies comparing the failure rate when performing either the PMRT to TTE approach or the PMRT to the PI one. In order to ensure a better overall understanding we have calculated the odds ratio (OR) in every single study (PMRT to TTE versus PMRT to PI) as well as the weighted average of the ORs with $95 \%$ confidence intervals. The results are presented in a forest plot considering both a fixed and a random effect models. A sensitivity test by eliminating studies one by one is also performed. Finally, funnel plot and asymmetry tests are done.

Secondly, we did a simple literature review in order to identify some variables possibly working as predicting factors for RF in the two different schemas. The differences in study designs made statistically complex to perform a multivariate meta-analysis.

The statistical software used was meta (39). A DerSimonian-Laird method was used for the meta-analysis and OR as measure of association. Statistical heterogeneity was analysed using the Mantel-Haenszel method/ $\mathrm{I}^{2}$ statistic. Statistical significance was defined as $\mathrm{P}<0.05$. High heterogeneity is defined as $\mathrm{I}^{2}>50 \%$.

The present study design followed PRISMA guidelines.

\section{Results}

\section{Literature review}

Some previous attempts to perform a meta-analysis about failure rate depending on the RT timing were found.

Lam et al. (35) published a paper in which three articles directly comparing failure rate in the RT to PI group versus RT to TTE were included. They obtained an OR of 0.13 (0.05-0.32) showing that failure was significantly lower 
(22.9\% versus $5.6 \%, \mathrm{P}=$ less than 0.0001$)$ when irradiating the PI. The sample population was 131 patients. One of the studies included was a prospective nonrandomized trial which found three risk factors for RF: T3-T4 tumours, smoking and positive axillary lymph node status (40). An important rate of patients undergoing the schema RT to TTE had received neoadjuvant chemotherapy due to their stage III or more advanced cancer. Both variables (neoadjuvant chemotherapy/Stage III-IV) might act as confounder factors for RF and RT to TTE.A clear limitation regarding the sample size is present in this study.

El-Sabawi et al. (36) presented a paper trying to evaluate outcomes following autologous and implantbased reconstruction in the setting of PMRT and adjuvant chemotherapy. A pooled analysis using study size means was used. A total population of 3,605 patients was included for the implant-based reconstruction group. No difference about immediate or delayed reconstruction was made in this group. The analysis demonstrated a failure rate of $18.8 \%$ when PMRT preceded the TTE to PI exchange (RT to TTE), compared to a rate of $14.7 \%$ if the radiation was delivered to the PI $(\mathrm{P}=0.006)$. In their paper they also analysed the impact of adjuvant chemotherapy on surgical outcomes. Results are unclear and further prospective and larger studies are required to elucidate if women requiring adjuvant chemotherapy have an increased risk of failure. This study included a larger number of studies leading to a better sample size. Otherwise, most of them are single arm studies with low levels of evidence and no direct comparison between the two groups. The resulting pooled analysis may conduct to wrong conclusions due to a different value of the weighting process.

Lee et al. (37) conducted a meta-analysis including 899 patients from double-arm previous studies directly comparing both schemas. Although they showed a tendency towards an increased risk of failure in the RT to TTE group (RR 1.72), their results were not statistically significant. They advocated larger population meta-analysis.

Ricci et al. (38) set in their study a double level analysis. In the first part, they conducted a pooled analysis from single arm studies data. They founded a failure rate of $20 \%$ versus $13.4 \%, \mathrm{P}=0.001$ when comparing $\mathrm{RT}$ to TTE versus $\mathrm{RT}$ to $\mathrm{PI}$. In the second part they did a meta-analysis with those studies that compared both groups, including a total population of 798 patients. They concluded a higher incidence of failure when the TTE was radiated: RR 2.33 (1.24-4.35), $\mathrm{P}=0.083$ for the random effect model; RR 2.31 (1.56-3.41), $\mathrm{P}<0.0001$ for the fixed effect model.
Ten articles were selected for our meta-analysis. All the studies included compare both groups, and no pooled analysis is done.

Anderson et al. (25) presented a failure rate of $4.8 \%$ when irradiating TTE, compared with a $0 \%$ failure rate when the radiation was applied to the $\mathrm{PI}(\mathrm{P}=0.21)$. No factors were significant predictors of failure. They hypothesized that their low failure rate could have been related with the use of intensity-modulated RT.

Nava et al. (26) demonstrated a statistically significant $(\mathrm{P}<0.0001)$ increase in $\mathrm{RF}$ when irradiating TTE compared with RT to PI (40\% vs. 6.4\%).

Collier et al. (27) didn't found any differences when comparing failure risk in both groups (6.3\% TTE vs. $4.5 \%$ PI; $\mathrm{P}=1$ ).

In their Cohorts study, Lentz et al. (28) showed up no differences when comparing failure $(13.6 \% \mathrm{RT}$ to PI vs. $20.6 \%$ RT to TTE, $\mathrm{P}=0.72)$. Current smoking was the only predictor they found to be associated with an overall increased risk of complication. In the second part of their article they attempted to demonstrate differences in RF when the TTE to PI exchange was done in the first 4 months after the PMRT or after more than 4 months (for the RT to TTE group) . Even when they found a tendency to an increased RF when doing the exchange in less than four months after the PMRT (25\% vs. $14.9 \%)$, the results were not statistically significant. Similarly, Peled et al. $(41,42)$ demonstrated a statistically significant increase in failure of $22.4 \%$ versus $7.7 \%, \mathrm{P}=0.036$, in the group undergoing the exchange earlier after the PMRT (first 6 months). Kronowitz et al. (43) also stated a higher failure rate when the TE was replaced earlier in the inflammatory period of the radiation. In the article by Fowble et al. (31) the interval to exchange since RT was found to be significant when measured dichotomously. The odds of failure were 6.375 times higher among those patients with an interval of less than three months (compared to the group of more than 3 months). They didn't found any difference when the interval to exchange was measured in a continuous manner.

Aristei et al. (29) published a failure rate of $10 \%$ when the TTE was irradiated, whereas the rate was $27 \%$ when the irradiated element was the PI $(\mathrm{P}=0.239)$. According to them, age emerged as a significant risk factor for prosthesis removal.

Cordeiro et al. (30) presented a paper in which the failure rate was $18.1 \%$ for the TTE group and $12.4 \%$ for the PI one. The difference was not statistically significant. 
Interestingly, they reported that the prescribed energy for a total dose of 50-50.4 Gy (180-200 cGy per fraction) was $6 \mathrm{MV}$ for the PI group and $15 \mathrm{MV}$ photons for the TTE group in order to minimize the "scatter" dose off the magnetic TTE valve.

In their article, Fowble et al. (31) reported a global RF rate of $18 \%$. The rate was $19.8 \%$ for the RT to TTE group and $7.7 \%$ for those patients in whom the irradiated implant was the PI. In univariate analysis they presented as the main risk factor for RF the absence of acellular dermal matrix $(\mathrm{ADM})$ or serratus muscle coverage at the time of radiation. Failure occurred in $9.1 \%$ of patients when it was present versus $32.5 \%$ of patients when it wasn't $(\mathrm{P}=0.0069)$. For the group of women with full coverage, the location of the mastectomy scar was found to be a risk factor; with a failure rate of $19.2 \%$ when the scar was located at the inframammary fold in contrast with a $0 \%$ rate when other location was used. In the multivariate logistic regression analysis, weight was the most significant factor. They presented an OR for fail of 5.25 among those patients with a weight under $120 \mathrm{lb}$, compared with those of more than $120 \mathrm{lb}(\mathrm{P}=0.0395)$. They speculate that lower weight might be an important factor for interaction of thin skin flaps, absence of ADM or serratus coverage, short interval to exchange and inframammary scar. Contrary to this, some papers found high IBM as a predicting factor for failure (44). The authors also provide some variables in which a nonstatistically significant association with an increased risk of RF was found: Diabetes, smoking, Nipple and areolar sparing mastectomies and hormonal/monoclonal treatments. They also mentioned an article (45) in which the use of chest wall RT boosts was found to be a significant failure predictor.

In the study by Yan et al. (32) a failure rate of $12.2 \%$ was found in the RT to TTE group compared with a $0.0 \%$ in the RT to PI cohort but the result was not statistically significant $(\mathrm{P}=0.57)$. In the article they point out some interesting references about the possible role of the inflation/deflation expander state when irradiating it on the RT to TTE group. A recent animal study (46) showed a higher epidermal atrophy, dermal inflammation, fibrosis and vascular changes when radiating deflated expanders in rabbits compared with those in which the expander was fully inflated. Recently, Woo et al. published a paper showing a statistically significant failure rate of $35 \%$ when deflated expanders were irradiated compared with a $6.9 \%$ rate when the radiation was applied to inflated expanders (47). Traditionally, it has been necessary to deflate, at least partially, the expander prior to the RT in order to improve dosage of the target field. Nowadays radiation technology has improved enough that several articles have shown successful outcomes with the application of RT to fully inflated expanders $(48,49)$.

According to Santosa et al. (33) timing of PMRT was not a significant predictor for failure. Their rate was $11.5 \%$ for the RT to TE group and $8.7 \%$ for the RT to PI one $(\mathrm{P}=0.9)$. They found older age and being a current or a former smoker to be significant predictors.

Ogita et al. (34) published a rate of $15.6 \%$ when radiating the TTE, versus a $10.2 \%$ when they radiated the PI $(\mathrm{P}=0.54)$.

The paper by Hvilsom et al. (50) was not included for meta-analysis as they compared results in both groups but in the setting of delayed reconstruction. Their results also showed and increased risk of failure when radiating the TTE.

\section{Meta-analysis}

The collected data from the ten studies are summarized in Table 1.

We performed a meta-analysis in two possible scenarios: a fixed-effect model and a random effect model (Figure 2). A high heterogeneity of $\mathrm{I}^{2}=51 \%$ was found $(\mathrm{P}=0.03)$. Thus, the random effect model is mainly considered. For the random effect model [Figure 3, meta-analysis (Random effect model)] the OR was 1.85 , but the result was not statistically significant $(0.96,3.57 ; \mathrm{P}=0.067)$. A size effect (z) of 1.83 was found. A sensitivity analysis is also performed (Figure 4). A significant OR of 2.32 would have been reached if we hadn't included the article by Aristei et al. Finally, a funnel plot is presented (Figure 5). A P value of 0.7345 was calculated for the linear regression test for funnel plot asymmetry. No publication bias exists.

Limitations of our paper include the fact that most of the papers collected for the meta-analysis presented retrospective data with a lack of patients recruited in a prospective and randomized approach. The definition of RF should be standardised to improve comparability between the studies.

\section{Conclusions}

There is a tendency towards a higher failure rate when the TTE is irradiated compared with the irradiation of the PI, but no strict statistical significance has been reached.

A deep understanding of complications risk versus 
Table 1 Reconstructive failure

\begin{tabular}{|c|c|c|c|c|c|c|c|}
\hline Author & Year & \multicolumn{2}{|c|}{ Total } & \multicolumn{2}{|c|}{ Reconstructive failure } & PMRT total & $\mathrm{p}$ \\
\hline Anderson & 2009 & 62 & 12 & 3 & 0 & 74 & 0.21 \\
\hline Nava & 2011 & 50 & 109 & 20 & 7 & 159 & 0.0001 \\
\hline Collier & 2014 & 32 & 22 & 2 & 1 & 54 & 1 \\
\hline Aristei & 2012 & 90 & 11 & 9 & 3 & 101 & 0.239 \\
\hline Cordeiro & 2015 & 94 & 210 & 17 & 26 & 304 & Unknown \\
\hline Fowble & 2015 & 86 & 13 & 17 & 1 & 99 & Unknown \\
\hline Yan & 2016 & 41 & 11 & 5 & 0 & 52 & 0.57 \\
\hline Total & & 625 & 505 & 97 & 50 & 1130 & \\
\hline
\end{tabular}

PMRT, postmastectomy radiation therapy; TE, tissue expander; PI, permanent implant.

$\begin{array}{lrrrr}\text { Study } & \begin{array}{r}\text { PRMT to TE } \\ \text { Events }\end{array} & \begin{array}{r}\text { PRMT to PI } \\ \text { Tovents }\end{array} & \text { Total } \\ \text { Anderson, 2009 } & 3 & 62 & 0 & 12 \\ \text { Nava,2011 } & 20 & 50 & 7 & 109 \\ \text { Collier, 2013 } & 2 & 32 & 1 & 22 \\ \text { Lentz, 2012 } & 7 & 34 & 3 & 22 \\ \text { Aristei, 2012 } & 9 & 90 & 3 & 11 \\ \text { Cordeiro, 2015 } & 17 & 94 & 26 & 210 \\ \text { Fowble, 2015 } & 17 & 86 & 1 & 13 \\ \text { Yan, 2016 } & 5 & 41 & 0 & 11 \\ \text { Santosa, 2016 } & 12 & 104 & 4 & 46 \\ \text { Ogita, 2017 } & 5 & 32 & 5 & 49 \\ & & & & \\ \text { Fixed effect model } & 97 & \mathbf{6 2 5} & \mathbf{5 0} & \mathbf{5 0 5} \\ \text { Random effects model } & & & \\ \text { Heterogeneity: } I^{2}=51 \%, \chi_{9}^{2}=18.36(P=0.03) \\ \text { Test for overall effect (fixed effect): } z=3.62(P<0.001) \\ \text { Test for overall effect (random effects): } z=1.83(P=0.067)\end{array}$

Figure 2 Meta-analysis: fixed and random effect models.

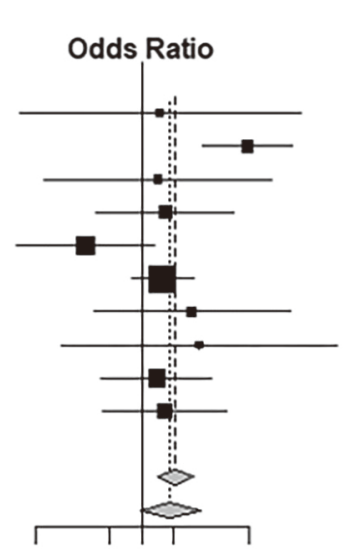

$\begin{array}{lll}0.1 & 0.512 \quad 10\end{array}$
OR $\quad 95 \%-\mathrm{Cl} \quad \begin{gathered}\text { Weight } \\ \text { (fixed) (random) }\end{gathered}$

$1.47[0.07 ; 30.29] \quad 2.2 \% \quad 3.9 \%$

$9.71[3.75 ; 25.17] \quad 7.4 \% \quad 15.4 \%$

$1.40[0.12 ; 16.46] \quad 3.1 \% \quad 5.4 \%$

$1.64[0.38 ; 7.17] \quad 8.1 \% \quad 10.6 \%$

$0.30[0.07 ; 1.32] \quad 13.5 \% \quad 10.5 \%$

$1.56[0.80 ; 3.04] \quad 36.9 \% \quad 18.4 \%$

$2.96[0.36 ; 24.33] \quad 3.9 \% \quad 6.8 \%$

$3.47[0.18 ; 67.55] \quad 1.9 \% \quad 4.0 \%$

$1.37[0.42 ; 4.50] \quad 13.7 \% \quad 13.1 \%$

$1.63[0.43 ; 6.16] \quad 9.3 \% \quad 11.8 \%$

$2.06[1.39 ; 3.06] 100.0 \%$

$1.85[0.96 ; 3.57] \quad-\quad 100.0 \%$ the potential benefits of immediate implant-based breast reconstruction is mandatory to improve the decision making process between the surgeon and the patients. In some women, the risk of complications may outweigh the benefit of this modality of reconstruction and thus, the predictive risk of failure should lead to avoid the combination of immediate reconstruction, implant-based approach and PMRT among them.

According to our literature review several factors could act as risk predictors for failure of this reconstructive modality. Smoker patients, older ones, those with presence Low BMI/High BMI, diabetic women and patients with advanced tumours (N2-3/T1/those requiring adjuvant or neoadjuvant chemotherapy) might be at a higher risk. Some surgery related indicators may include: early exchanges (time from PMRT to TTE-PI exchange less than 3-6 months), nipple/areolar sparing mastectomies, inframammary fold incision, partial implant coverage. 


\begin{tabular}{|c|c|c|c|c|}
\hline \multirow[b]{2}{*}{ Study } & \multicolumn{2}{|c|}{ PRMT to TE } & \multicolumn{2}{|c|}{ PRMT to PI } \\
\hline & Events & Total Ev & nts & Total \\
\hline Anderson, 2009 & 3 & 62 & 0 & 12 \\
\hline Nava,2011 & 20 & 50 & 7 & 109 \\
\hline Collier, 2013 & 2 & 32 & 1 & 22 \\
\hline Lentz, 2012 & 7 & 34 & 3 & 2 \\
\hline Aristei, 2012 & 9 & 90 & 3 & 1 \\
\hline Cordeiro, 2015 & 17 & 94 & 26 & 210 \\
\hline Fowble, 2015 & 17 & 86 & 1 & \\
\hline Yan, 2016 & 5 & 41 & 0 & \\
\hline Santosa, 2016 & 12 & 104 & 4 & \\
\hline Ogita, 2017 & 5 & 32 & 5 & \\
\hline $\begin{array}{l}\text { Random effects model } \\
\text { Heterogeneity: } I^{2}=51 \%, \chi_{9}^{2} \\
\text { Test for overall effect: } z=1\end{array}$ & $\begin{array}{r}97 \\
2=18.36 \\
1.83(P=\end{array}$ & $\begin{array}{l}625 \\
P=0.03)\end{array}$ & 50 & 505 \\
\hline
\end{tabular}

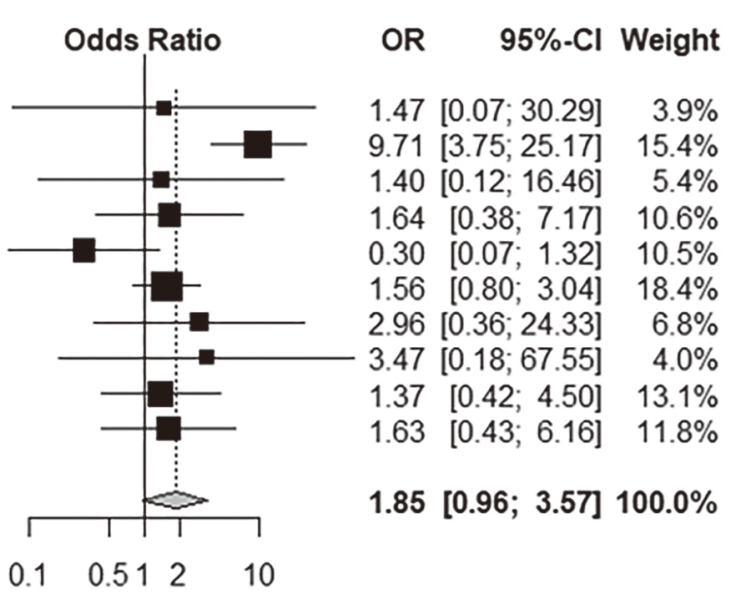

Figure 3 Meta-analysis (random effect model).

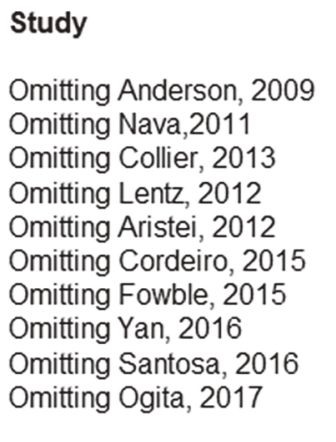

Random effects model

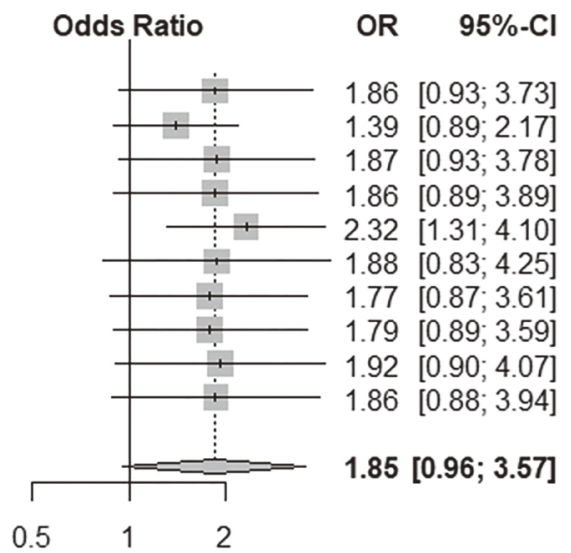

Figure 4 Sensitivity analysis (random effect model).

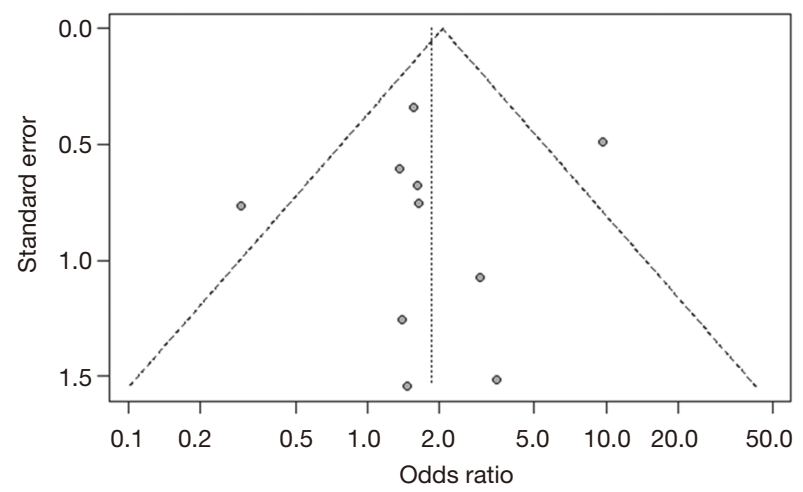

Figure 5 Funnel plot (random effect model).
Finally, some radiotherapy characteristics may also act as risk factors for RF: conventional RT (as compared with intensity modulated RT), high photons energy RT, deflated expanders at the time of RT, presence of chest wall RT Boost.

Further prospective and standardized studies trying to elucidate the influence of these suggested risk factors for outcome of RF have to be performed in order to establish a consensus about the indications and contraindications of this reconstructive modality. This will allow setting a protocol to help the surgeons to decide when to perform or delay an implant-based reconstruction and to individualize 
the best PMRT timing approach for each patient.

\section{Acknowledgments}

Funding: None.

\section{Footnote}

Conflicts of Interest: All authors have completed the ICMJE uniform disclosure form (available at http://dx.doi. org/10.21037/gs.2020.01.20). The authors have no conflicts of interest to declare.

Ethical Statement: The authors are accountable for all aspects of the work in ensuring that questions related to the accuracy or integrity of any part of the work are appropriately investigated and resolved.

Open Access Statement: This is an Open Access article distributed in accordance with the Creative Commons Attribution-NonCommercial-NoDerivs 4.0 International License (CC BY-NC-ND 4.0), which permits the noncommercial replication and distribution of the article with the strict proviso that no changes or edits are made and the original work is properly cited (including links to both the formal publication through the relevant DOI and the license). See: https://creativecommons.org/licenses/by-nc-nd/4.0/.

\section{References}

1. Albornoz CR, Cordeiro PG, Pusic AL, et al. Diminishing Relative Contraindications for Immediate Breast Reconstruction: A Multicenter Study. J Am Coll Surg 2014;219:788-95.

2. Jagsi R, Jiang J, Momoh A, et al. Trends and Variation in Use of Breast Reconstruction in Patients With Breast Cancer Undergoing Mastectomy in the United States. J Clin Oncol 2014;32:919-26.

3. Ho AY, Hu ZI, Mehrara BJ, et al. Radiotherapy in the setting of breast reconstruction: types, techniques, and timing. Lancet Oncol 2017;18:e742-53.

4. EBCTCG (Early Breast Cancer Trialists' Collaborative Group). Effect of radiotherapy after mastectomy and axillary surgery on 10-year recurrence and 20-year breast cancer mortality: meta-analysis of individual patient data for 8135 women in 22 randomized trials. Lancet 2014;383:2127-35.

5. Boyages J, Langlands A. Postmastectomy radiation therapy: better late than never. Aust N Z J Surg 1998;68:550-3.

6. Ragaz J, Jackson S, Le N, et al. Adjuvant Radiotherapy and Chemotherapy in Node-Positive Premenopausal Women with Breast Cancer. N Engl J Med 1997;337:956-62.

7. Overgaard M, Hansen P, Overgaard J, et al. Postoperative Radiotherapy in High-Risk Premenopausal Women with Breast Cancer Who Receive Adjuvant Chemotherapy. N Engl J Med 1997;337:949-55.

8. Albornoz CR, Bach PB, Mehrara BJ, et al. A paradigm shift in U.S. Breast reconstruction: Increasing implant rates. Plast Reconstr Surg 2013;131:15-23.

9. Chetta MD, Aliu O, Zhong L, et al. Reconstruction of the Irradiated Breast. Plast Reconstr Surg 2017;139:783-92.

10. Kronowitz SJ, Robb GL. Radiation therapy and breast reconstruction: A critical review of the literature. Plast Reconstr Surg 2009;124:395-408.

11. Cordeiro PG, Albornoz CR, McCormick B, et al. The impact of postmastectomy radiotherapy on two-stage implant breast reconstruction: an analysis of long-term surgical outcomes, aesthetic results, and satisfaction over 13 years. Plast Reconstr Surg 2014;134:588-95.

12. Agarwal S, Kidwell K, Farberg A, et al. Immediate Reconstruction of the Radiated Breast: Recent Trends Contrary to Traditional Standards. Ann Surg Oncol 2015;22:2551-9.

13. Sekiguchi K, Kawamori J, Yamauchi H. Breast reconstruction and postmastectomy radiotherapy: complications by type and timing and other problems in radiation oncology. Breast Cancer 2017;24:511-20.

14. Steele KH, Macmillan RD, Ball GR, et al. Multicentre study of patient-reported and clinical outcomes following immediate and delayed Autologous Breast Reconstruction And Radiotherapy (ABRAR study). J Plast Reconstr Aesthet Surg 2018;71:185-93.

15. Jassem J. Post-mastectomy radiation therapy after breast reconstruction: Indications, timing and results. Breast 2017;34:S95-8.

16. Berbers J, van Baardwijk A, Houben R, et al. 'Reconstruction: Before or after postmastectomy radiotherapy?' A systematic review of the literature. Eur J Cancer 2014;50:2752-62.

17. Baschnagel AM, Shah C, Wilkinson J, et al. Failure Rate and Cosmesis of Immediate Tissue Expander/Implant Breast Reconstruction After Postmastectomy Irradiation. Clin Breast Cancer 2012;12:428-32.

18. El-Sabawi B, Carey J, Hagopian T, et al. Radiation and breast reconstruction: Algorithmic approach and evidencebased outcomes. J Surg Oncol 2016;113:906-12. 
19. Archambeau JO, Pezner R, Wasserman T. Pathophysiology of irradiated skin and breast. Int J Radiat Oncol Biol Phys 1995;31:1171-85.

20. Kronowitz SJ. Current status of implant-based breast reconstruction in patients receiving postmastectomy radiation therapy. Plast Reconstr Surg 2012;130:513e-23e.

21. Vandeweyer E, Deraemaecker R. Radiation therapy after immediate breast reconstruction with implants. Plast Reconstr Surg 2000;106:56-8.

22. Berry T, Brooks S, Sydow N, et al. Complications rates on radiation on tissue expander and autologous tissue breast reconstruction. Ann Surg Oncol 2010;17:202-10.

23. Ribuffo D, Monfrecola A, Guerra M, et al. Does postoperative radiation therapy represent a contraindication to expander-implant based immediate breast reconstruction? An update 2012-2014. Eur Rev Med Pharmacol Sci 2015;19:2202-7.

24. Tsoutsou PG, Koukourakis M, Azria D, et al. Optimal timing for adjuvant radiation therapy in breast cancer. Crit Rev Oncol Hematol 2009;71:102-16.

25. Anderson PR, Freedman G, Nicolaou N, et al. Postmastectomy Chest Wall Radiation to a Temporary Tissue Expander or Permanent Breast Implant-Is There a Difference in Complication Rates? Int J Radiat Oncol Biol Phys 2009;74:81-5.

26. Nava MB, Pennati A, Lozza L, et al. Outcome of Different Timings of Radiotherapy in Implant-Based Breast Reconstructions. Plast Reconstr Surg 2011;128:353-9.

27. Collier P, Williams J, Edhayan G, et al. The effect of timing of postmastectomy radiation on implant-based breast reconstruction: a retrospective comparison of complication outcomes. The American Journal of Surgery 2014;207:408-11.

28. Lentz R, Ng R, Higgins S, et al. Radiation Therapy and Expander-Implant Breast Reconstruction. Ann Plast Surg 2013;71:269-73.

29. Aristei C, Falcinelli L, Bini V, et al. Expander/implant breast reconstruction before radiotherapy. Strahlenther Onkol 2012;188:1074-9.

30. Cordeiro PG, Albornoz C, McCormick B, et al. What Is the Optimum Timing of Postmastectomy Radiotherapy in Two-Stage Prosthetic Reconstruction? Plast Reconstr Surg 2015;135:1509-17.

31. Fowble B, Park C, Wang F, et al. Rates of Reconstruction Failure in Patients Undergoing Immediate Reconstruction With Tissue Expanders and/or Implants and Postmastectomy Radiation Therapy. Int J Radiat Oncol Biol Phys 2015;92:634-41.
32. Yan C, Fischer J, Freedman G, et al. The Timing of Breast Irradiation in Two-Stage Expander/Implant Breast Reconstruction. Breast J 2016;22:322-9.

33. Santosa KB, Chen X, Qi J, et al. Postmastectomy Radiation Therapy and Two-Stage Implant-Based Breast Reconstruction. Plast Reconstr Surg 2016;138:761-9.

34. Ogita M, Nagura N, Kawamori JH, et al. Risk factors for complications among breast cancer patients treated with post-mastectomy radiotherapy and immediate tissue-expander/permanent implant reconstruction: a retrospective cohort study. Breast Cancer 2018;25:167-75.

35. Lam TC, Hsieh F, Boyages J. The Effects of Postmastectomy Adjuvant Radiotherapy on Immediate Two-Stage Prosthetic Breast Reconstruction. Plast Reconstr Surg 2013;132:511-8.

36. El-Sabawi B, Sosin M, Carey J, et al. Breast reconstruction and adjuvant therapy: A systematic review of surgical outcomes. J Surg Oncol 2015;112:458-64.

37. Lee KT, Mun G. Optimal Sequencing of Postmastectomy Radiotherapy and Two Stages of Prosthetic Reconstruction: A Meta-analysis. Ann Surg Oncol 2017;24:1262-8.

38. Ricci JA, Epstein S, Momoh A, et al. A meta-analysis of implant-based breast reconstruction and timing of adjuvant radiation therapy. J Surg Res 2017;218:108-16.

39. Schwarzer G. meta: An R Package for Meta-Analysis. R News 2007;7:40-5.

40. Cowen D, Gross E, Rouannet P, et al. Immediate post-mastectomy breast reconstruction followed by radiotherapy: risk factors for complications. Breast Cancer Res Treat 2010;121:627-34.

41. Peled AW, Foster R, Esserman L, et al. Increasing the Time to Expander-Implant Exchange after Postmastectomy Radiation Therapy Reduces ExpanderImplant Failure. Plast Reconstr Surg 2012;130:503-9.

42. Peled AW, Sears M, Wang F, et al. Complications After Total Skin-Sparing Mastectomy and Expander-Implant Reconstruction: Effects of Radiation Therapy on the Stages of Reconstruction. Ann Plast Surg 2018;80:10-3.

43. Kronowitz SJ, Lam C, Terefe W, et al. A Multidisciplinary Protocol for Planned Skin-Preserving Delayed Breast Reconstruction for Patients with Locally Advanced Breast Cancer Requiring Postmastectomy Radiation Therapy: 3-Year Follow-Up. Plast Reconstr Surg 2011;127:2154-66.

44. Hirsch EM, Seth AK, Kim JY, et al. Analysis of risk factors for complications in expander/implant breast reconstruction by stage of reconstruction. Plast Reconstr Surg 2014;134:692e-9e.

45. Woody NM, Durand P, Naik M. Impact of breast 
radiotherapy on late toxicities and reoperation following mastectomy with tissue expander based reconstruction. Int J Radiat Oncol Biol Phys 2014;90:S46.

46. Celet Ozden B, Guven E, Aslay I, et al. Does partial expander deflation exacerbate the adverse effects of radiotherapy in two-stage breast reconstruction? World J Surg Oncol 2012;10:44.

47. Woo KJ, Paik J, Bang S, et al. The Impact of Expander Inflation/Deflation Status During Adjuvant Radiotherapy on the Complications of Immediate Two-Stage Breast Reconstruction. Aesthetic Plast Surg 2017;41:551-9.

48. Ascherman JA, Hanasono MM, Newman MI, et al.

Cite this article as: Fuertes V, Francés M, Casarrubios JM, Fernández-Palacios J, González JM, Loro-Ferrer JF. Implantbased immediate breast reconstruction: failure rate when radiating the tissue expander or the permanent implanta meta-analysis. Gland Surg 2020;9(2):209-218. doi: 10.21037/ gs.2020.01.20
Implant Reconstruction in Breast Cancer Patients Treated with Radiation Therapy. Plast Reconstr Surg 2006;117:359-65.

49. Piroth MD, Piroth DM, Pinkawa M, et al. Immediate Reconstruction with an Expander/Implant Following Ablatio Mammae because of Breast Cancer. Strahlenther Onkol 2009;185:669-74.

50. Hvilsom GB, Hölmich LR, Steding-Jessen M, et al. Delayed breast implant reconstruction: is radiation therapy associated with capsular contracture or reoperations? Ann Plast Surg 2012;68:246-52. 